\title{
Pesticide Transport in Runoff Comparison with Convolution Model for Mackay Whitsunday Region.
}

\author{
$\underline{\text { F.J. Cook }}^{\text {a,b,c,d }}$, K.W. Rohde ${ }^{\mathrm{e}}$ and D.M. Silburn ${ }^{\mathrm{f}}$ \\ ${ }^{a}$ Freeman J Cook and Associates Pty Ltd, ${ }^{b}$ eWater Cooperative Research Centre, ${ }^{c}$ CSIRO Land and Water, \\ Dutton Park, Queensland, ${ }^{d}$ The University of Queensland, ${ }^{e}$ Dept. of Environment and Resource \\ Management, Mackay, Queensland, ${ }^{f}$ Dept. of Environment and Resource Management,, Toowoomba, \\ Queensland \\ Email:freeman.j.cook@gmail.com)
}

Pesticides in sugarcane dominated catchments are applied for a period of a few months during the harvesting period (July-November) to control weeds post-harvest. This means that individual blocks within the catchment receive pesticides on different dates. Given first-order kinetics for the decay of the concentration in the surface layer (cane trash + soil), then across the catchment, the concentration on the blocks will be a patchwork. When a rainfall event occurs that induces runoff, the pesticide in the runoff will be sampled from this patchwork of block pesticide concentrations which will then get mixed at the drainage system and then catchment scales. Recently Cook et al. (2011) used convolution integrals to show how this patchwork of concentrations would manifest in runoff at catchment scales given an application distribution function, application time period less than the frequency of application, and half-life of the pesticide. This approach provides a means to understand the difference in the pesticide concentrations found in block runoff studies and in rivers.

Recent studies in the Paddock to Reef Monitoring, Modelling and Reporting Program (Carroll et al., 2011) have provided a data set for testing the model of Cook et al. (2011). This data set provides information on pesticide concentrations in runoff from individual blocks, multiple blocks and multiple farms which have been monitored in the Mackay region. The results from this study allow us to compare the predicted concentrations in runoff derived from the convolution model with measurements in terms of the dilutions seen at the multi-farm compared to the block scale. This allows an estimate of the half-life to be determined.

The model allows the half-life of the pesticide to be estimated and compared across the multi-farm, multiblock and block scales. The results indicate the block scale measurements give greater half-lives than are found at the multi-block and multi-farm scales. At the block scale the pesticide can be considered to be applied as a pulse, whereas at larger scales a cosine application function is more appropriate (Cook et al., 2011). The half-life values across scales are not significantly different at the $5 \%$ level except for atrazine. This could be due to the variation in soil properties at the larger scales or other factors such as lower application rates, mixing processes or decay in the water. What this does suggest, however, is that at these larger scales the half-life may be less than what is found in individual plot studies. The half life for atrazine of 9 days found when used in both the convolution and pulse models fitted the measured scaled runoff concentrations well. The half-life of 36 days obtained from the block data using the pulse model overestimated the scaled block concentrations. This suggests that in ecological risk analysis for water bodies the use of half-lives based on plot studies may be biased due to an underestimation of the decay rate of the pesticides.

Keywords: $\quad$ Runoff, herbicides, half-lives, scaling 


\section{INTRODUCTION}

The loss of pesticides (particularly herbicides) from soil to surface water is of importance in the Great Barrier Reef (GBR) lagoon as pesticides (pesticides are here taken to mean herbicides, insecticides and other chemicals used to control flora and fauna pests) have been found in the waters of the lagoon at detectable levels for several weeks after river floods (Lewis et al., 2009; Packett et al., 2009). Some pesticides have been found to persist at low concentrations $\left(1-10 \mathrm{ng} \mathrm{L}^{-1}\right)$ in the GBR throughout the year (Shaw et al., 2010). These pesticides are considered to constitute a possible threat to the GBR ecosystem (Lewis et al., 2009). Herbicides in runoff are of particular concern due to their possible impacts on nontarget species such as corals (Jones, 2005) and seagrass (Haynes et al., 2000). Lewis et al. (2009) also found herbicides in water ways (rivers and streams) but at concentrations an order of magnitude higher than in the estuary. The reduced concentrations in flood plumes (estuary) will be due in part to dilution (from runoff from areas where no pesticide was applied) but also due to a mixing of different pesticide concentrations from different blocks. Pesticides tend to be applied in a region (multiple blocks) over an application window which is shorter than the frequency of application. In sugarcane this tends to be after the harvesting of the crop in an approximately 4-5 month period from July to November. This means that blocks within a catchment would have had pesticide applied at a range of different times and the concentration in the surface soil will be at a range of concentrations due to the amount of decay that has occurred.

Recently Cook et al. (2011) published a solution to the up-scaling of pesticides from block scale to catchment scale using convolution integrals. They showed that for a cosine application function (the most appropriate for the sugarcane industry) the concentration could be described by (Cook et al., 2011):

$$
M^{*}(t)=\left\{\begin{array}{ll}
M_{0} \exp (-\mu t)+\frac{\left[\lambda^{2}(1-\exp (-\mu t))+\mu^{2}(1-\cos (\lambda t))-\mu \lambda \sin (\lambda t)\right]}{\mu t_{3}\left(\lambda^{2}+\mu^{2}\right)}, & 0<t \leq t_{3} \\
\left(M_{0}+\frac{\lambda^{2}\left[\exp \left(\mu t_{3}\right)-1\right]}{\mu t_{3}\left(\lambda^{2}+\mu^{2}\right)}\right) \exp (-\mu t), & t_{3}<t \leq T
\end{array},\right.
$$

where $M^{*}(t)=M(t) / M_{a}$ is the dimensionless mass of pesticide, $M(t)$ is mass of pesticide [M L $\left.{ }^{-2}\right]$ at time $t[\mathrm{~T}], M_{a}$ is the mass applied per unit area[ $\left.\mathrm{M} \mathrm{L}^{-2}\right), M_{0}$ is the residual mass remaining prior to the next application and can be calculated by (Cook et al., 2011):

$$
M_{0}=\frac{\lambda^{2}\left[\exp \left(\mu t_{3}\right)-1\right]}{\mu t_{3}\left(\lambda^{2}+\mu^{2}\right)[\exp (\mu T)-1]},
$$

$\lambda=2 \pi / t_{3}, t_{3}$ is the application period [T], $\mu=\ln (2) / t_{1 / 2}, t_{1 / 2}$ is the half-life of the pesticide [T] and $T$ is the frequency of application [T]. The second part of eqn (1) can be rewritten as:

$$
M^{*}(t)=\left(M_{0}+\frac{\lambda^{2}\left[\exp \left(\mu t_{3}\right)-1\right]}{\mu t_{3}\left(\lambda^{2}+\mu^{2}\right)}\right) \exp (-\mu t)=A \exp (-\mu t)
$$

Cook et al. (2011) suggested that after the application period has ceased $\left(t>t_{3}\right)$ and prior to the next application period starting $(t<T)$, eqn (3) can be used to determine the half-life of the pesticide from runoff concentration data as a function with time from the blocks or in rivers during a runoff event. This suggested technique will be tested here.

The Paddock to Reef Monitoring, Modelling and Reporting Program (Carroll et al., 2011) was devised to provide better information for changing land management practices to improve the water quality reaching the GBR. One of the areas where this Program is being implemented is in the Mackay Whitsunday region (Rohde and Bush, 2011) and the monitoring being carried out provides a data set which can be used to assess the convolution model. Monitoring at block (4 cane rows by $250 \mathrm{~m}$ length), multi-block and multifarm scales at one site (Marian) and at the other site (Victoria Plains) monitoring occurred at only the block scale. These data sets will be used to determine the half-life of various pesticides at different scales. 


\section{METHODS}

\subsection{Site and Soil}

The Marian site (Farm 3120, Block 2-2) is located near North Eton, SW of Mackay (21 ${ }^{\circ} 13^{\prime} 37^{\prime \prime} S 148^{\circ} 58^{\prime}$ $17^{\prime \prime} \mathrm{E}$ ). Slope is $0.4 \%$, draining to the north. The soil is a duplex derived from quaternary alluvium and has been previously mapped as mapping unit "Ma1" (Marian, yellow B horizon variant) (Holz and Shields 1984), which is a Brown Chromosol (Australian Soil Classification) (Isbell 1996).

The Victoria Plains site (Farm 3434A, Block 14-1) is located near Mt. Vince, west of Mackay (21 ${ }^{\circ} 11^{\prime}$ 3"S $\left.148^{\circ} 58^{\prime} 7^{\prime \prime} \mathrm{E}\right)$. The block has a slope of $1.1 \%$, draining to the south. The soil has previously been mapped $(1: 100,000)$ on the change between a Victoria Plains and Wollingford soil (Holz and Shields 1984) however further soil sampling confirmed that the selected block is exclusively a Victoria Plains soil. A Victoria Plains soil is a uniform clay derived from quaternary alluvium.

\subsection{Treatments}

Details of these treatments can be found in Rohde and Bush (2011). Here we only the herbicides treatments of interest. At the Marian site two treatments received atrazine and diuron at a rate of $1980 \mathrm{~g} \mathrm{ha}^{-1}$ each on 28/10/2009 but applied in different methods and in combination with other herbicides depending on the treatment. The Victoria Plains site received diuron and hexazinone at rates of 1872 and $528 \mathrm{~g} \mathrm{ha}^{-1}$, respectively but no atrazine. Various treatments with regard to tillage, bed width and nutrient application were included in combination with herbicide management.

\subsection{Monitoring}

Details of the monitoring can be found in Rohde and Bush, (2011) and only a brief description will be given here. Runoff samples were collected from each block using an ISCO automatic sampler which was connected to a datalogger and triggered by the amount of cumulative runoff $(3 \mathrm{~mm})$ passing through a San Dimas flume. This same method was used at both the Marian and Victoria Plains sites.

At the multi-block scale samples were collected from a farm drain (catchment area approximately 53.5 ha) and the flow measured using a 1 in 40 flat "vee" crest weir. Samples were again triggered for collection for every $3 \mathrm{~mm}$ of cumulative runoff. At the multi-farm scale runoff was measured within a natural drain (catchment area approximately 2965 ha) using a 1 in 20 flat "vee" crest weir, with depth of flow again recorded at one minute intervals. The water samples were again collected for every $3 \mathrm{~mm}$ of runoff. Samples from all sites were refrigerated prior to collection and analysis (see Rohde and Bush, 2011 for details).

\subsection{Analysis}

The data were analysed using eqn (3) assuming that the concentration was representative of the mass in the surface soil. Cook et al. (2011) showed that using approximations suggested by Silburn and Kennedy (2007), the relationship between the mass in the surface soil and concentration in the runoff $\left(C_{R O}\left[\mathrm{M} \mathrm{L}^{-3}\right]\right)$ can be described by:

$$
C_{R 0}=\frac{\eta}{\rho_{b}}\left(\frac{M^{*} M_{a}}{z A_{i}}\right)^{\beta}
$$

where $z$ is the depth of surface soil layer [L], $A_{i}$ is unit area $\left[\mathrm{L}^{2}\right] \eta$ and $\beta$ are empirical constants, and $\rho_{\mathrm{b}}$ is the bulk density of the soil $\left[\mathrm{M} \mathrm{L}^{-3}\right]$. Substituting eqn (4) into eqn (3) and collecting the constant terms gives:

$$
C_{R O}=B \exp (-a t)
$$

where $B$ is the collected constants and $a=\beta \mu$. This means that the value of $a$ can be obtained by a log linear fit to the data of $C_{R O}$ and $t$. The half-life can then be calculated by $t_{1 / 2}=-\ln (2) \beta / a$. Silburn and 
Kennedy (2007) suggested a value for $\beta$ of 1 while Leonard et al. (1979) suggested a value of 1.2. The $t_{1 / 2}$ values presented here will be calculated with $\beta=1$.

\section{RESULTS AND DISCUSSION}

The effect of the convolution (many blocks) compared to a pulse (eqn (3) with $A=1$ ), applicable at the block scale, shows that the shape of the mass of pesticide found in the top soil with time will change along with the peak height and position (Figure 1). This same shape can be seen in the results from the multi-farm concentrations when compared to the block and multi-block concentrations for four of the herbicides measured at the Marian site (Figure 2 ). The most runoff data were generated from treatment 2 at the Marian site. This was compared for diuron, ametryn and hexazinone with the multi-block and multi-farm results. These block data seem low compared to the multi-block and multi-farm data. This low concentration is mainly due to the 88 days elapsed since the application until the first runoff sample. The multi-block in particular displays the classic first-order decay behaviour as indicated by the shape of pulse curve in Figure 1. This is due to the first runoff samples being generated only approximately 7 days after application (Figure 2).

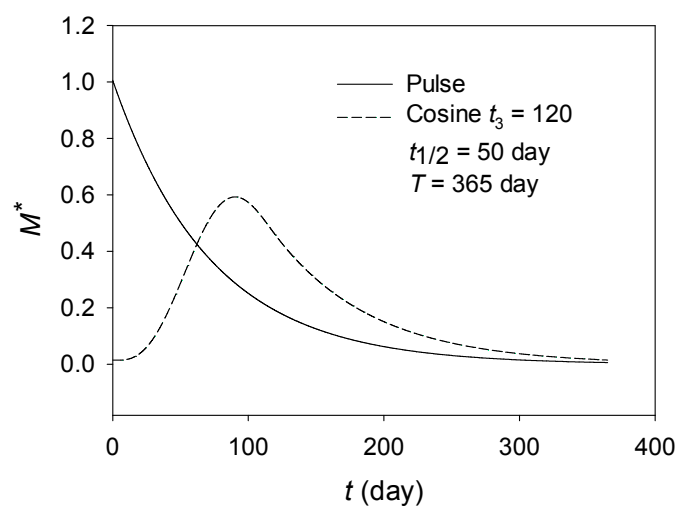

Figure 1. Comparison of the relative mass in the topsoil for a block (pulse applied at $t=0$ ) and catchment (cosine) using the convolution upscaling.

The half-life of the pesticides was estimated at both the Marian and Victoria Plains sites using eqn (5) for the range of pesticides measured at both sites. Interestingly although no atrazine was applied to the Victoria Plains blocks atrazine was detected in runoff and along with its breakdown products desethyl atrazine and desisopropyl atrazine which were found at both sites. This suggests that there must be some residual mass still in the soil or coming from other sources. The results are consistent across the sites but show a tendency to lower half-lives as we move up in scale (Table 1).

This tendency to lower values of half-lives as the scale increases may be due to other processes occurring at the larger scales, such as interactions with cane trash (Selim and Zhu, 2005), dilution, decay within the water, sediment deposition, and filtering (Willis et al. 1987; Finlayson and Silburn, 1996). The fact that we are sampling the 'tail' of the decay curve as the first runoff data is 88 days after application may also make this data less reliable. However, the block data are the least reliable as determined by the coefficient of regression and there is no significant difference between the results across the scales at the 5\% level except for atrazine (Table 1). The half-life values for atrazine determined at the block level are similar to the value of 29 days used by Cook et al. (2011) in their calculations based on the values suggested by PPDB (2009). The multiblock and multi-farm levels are less than $1 / 2$ of this value with 9 days for both. This suggests that the breakdown or loss seen at these larger scales could be different. However, the noise in the block scale measurements mean there is not a significant difference (at $5 \%$ level) between the block, multi-block and multi-farm scale measurements. These lower half-lives suggest that further investigation would be warranted. The atrazine breakdown products (desthyl atrazine and desisopropyl atrazine) are found at all sites and all scales of measurement.

Dilution in the multi-farm data due to areas that do not have pesticide applied could also affect the results. This will only be a problem if the proportion of dilution changes with the runoff event. This could occur where the catchment area has a large proportion of hard surfaces such as roads and buildings, which will cause greater proportional dilution during smaller runoff events. The multi-farm site has a catchment area of 2965 ha (Rohde and Bush, 2011), so this effect is less likely to be significant in a catchment of this size. The fact that atrazine, desthyl atrazine and desisopropyl atrazine are found at the Victoria Plains site, where no atrazine was applied, suggests this is either due to residual amounts from previous farming operations or other sources such as residues in spray equipment. Even with the half-life suggested here atrazine can still be found at measureable levels up to 1 year after applications have ceased. The results presented here suggest 
that the use of concentration data collected at multi-block and multi-farm (catchment) scales can give useful data on average half-lives of pesticides at such larger scales. Smith et al. (2011) have also shown that the method presented here is able to give estimates of the half-lives of pesticides at catchment scales.

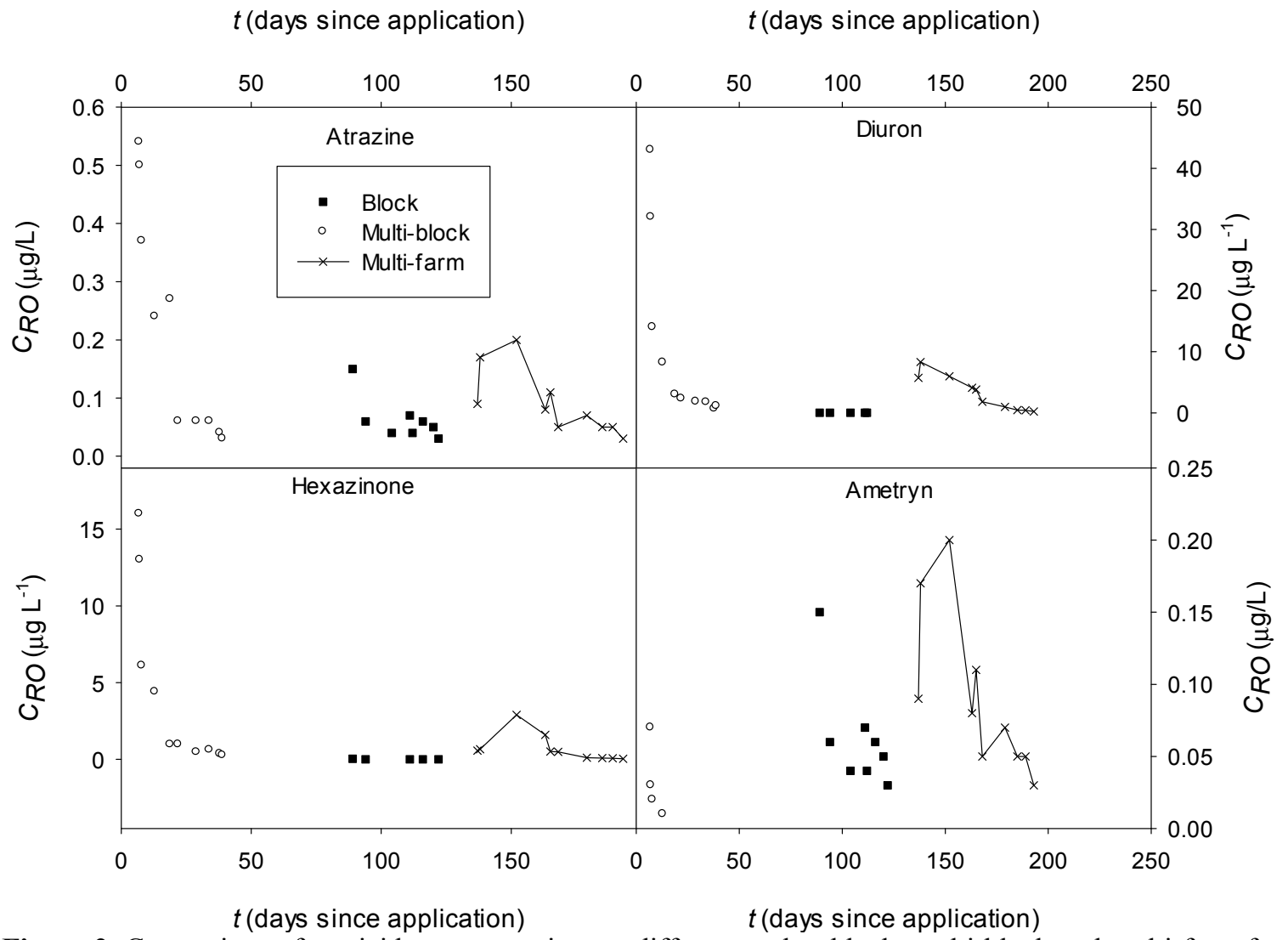

Figure 2. Comparison of pesticide concentrations at different scales, block, multi-block and multi-farm for four pesticides at the Marian site during runoff events. The application time for the block was 28/10/2009 and 18/01/2010 for the multi-block. The multi-farm data assumed that applications started on 15 July 2009.

Table 1. Half-life of various pesticides (in days) determined using eqn (5) with $\beta=1$. The Victoria Plains block values are presented in the brackets. The values followed by the same letter are not significantly different at the $5 \%$ level. Some values could not be determined (nd) due to lack of data.

\begin{tabular}{|c|c|c|c|c|c|c|c|c|c|}
\hline \multirow{3}{*}{ Pesticide } & \multicolumn{9}{|c|}{ Half -life (day) } \\
\hline & \multicolumn{3}{|c|}{$\begin{array}{l}\text { Marian (Victoria Plains) } \\
\text { block }\end{array}$} & \multicolumn{3}{|c|}{ Marian multi-block } & \multicolumn{3}{|c|}{ Marian multi-farm } \\
\hline & Mean & SE & $r^{2}$ & Mean & SE & $r^{2}$ & Mean & SE & $r^{2}$ \\
\hline Ametryn & $17^{\mathrm{a}}$ & 3 & 0.745 & $3^{\mathrm{a}}$ & 2 & 0.655 & $20^{\mathrm{a}}$ & 5 & 0.774 \\
\hline Atrazine & $\begin{array}{l}36^{\mathrm{a}} \\
\left(24^{\mathrm{a}}\right) \\
\end{array}$ & $16(7)$ & $\begin{array}{l}0.381 \\
(0.523)\end{array}$ & $9^{b}$ & 1 & 0.938 & $9^{b}$ & 1 & 0.922 \\
\hline $\begin{array}{l}\text { Desethyl } \\
\text { Atrazine }\end{array}$ & $\begin{array}{l}23^{\mathrm{a}} \\
\left(11^{\mathrm{a}}\right)\end{array}$ & $6(4)$ & $\begin{array}{l}0.617 \\
(0.581)\end{array}$ & $16^{\mathrm{ab}}$ & 5 & 0.648 & $9^{b}$ & 1 & 0.980 \\
\hline $\begin{array}{l}\text { Desisopropyl } \\
\text { Atrazine }\end{array}$ & $\begin{array}{l}19^{\mathrm{a}} \\
\left(10^{\mathrm{a}}\right)\end{array}$ & $6(6)$ & $\begin{array}{l}0.532 \\
(0.627)\end{array}$ & nd & nd & $\mathrm{Nd}$ & $10^{\mathrm{a}}$ & 1 & 0.960 \\
\hline Diuron & $\left(14^{\mathrm{a}}\right)$ & (3) & $(0.637)$ & $7^{\mathrm{a}}$ & 1 & 0.832 & $10^{\mathrm{a}}$ & 1 & 0.930 \\
\hline Hexazinone & $\left(6^{\mathrm{a}}\right)$ & (2) & $(0.625)$ & $7^{\mathrm{a}}$ & 1 & 0.840 & $7^{\mathrm{a}}$ & 1 & 0.954 \\
\hline Metolachlor & (7) & (2) & $(0.574)$ & nd & nd & nd & nd & nd & nd \\
\hline
\end{tabular}


The convolution for atrazine was calculated based on an application period of 153 days (July to November) and a half-life of 9 days (Table 1). This was compared with the multi-farm data runoff concentrations scaled by the maximum expected concentration of $46 \mu \mathrm{g} \mathrm{L} \mathrm{L}^{-1}$. The maximum concentration was calculated with eqn (4) using a bulk density of $1300 \mathrm{~kg} \mathrm{~m}^{-3}$, topsoil depth $(x)$ of $0.1 \mathrm{~m}$, and after Silburn and Kennedy (2007) $\beta=1$ and $\eta=28$. Similarly the scaled block concentrations were calculated using the same maximum concentration with the pulse model (eqn (3)) and compared with estimated concentrations for half-lives of 36 and 9 days.

The results for concentration are plotted on a log scale to give a better comparison. They show a good fit between the convolution and multi-farm data (Figure 3). The pulse model when using a half-life of 36 days did not match the block data (Figure 3) with the concentrations being overestimated. However, when the half-life of 9 days was used the pulse model gave results which were closer to the block data. This suggests that the half-life of 9 days calculated from the multi-farm data better reproduces concentrations found at the block scale. As stated earlier this is probably due to the first runoff data at the block scale being a considerable time after application with resulting concentrations being closer to the detection limit and more variable.

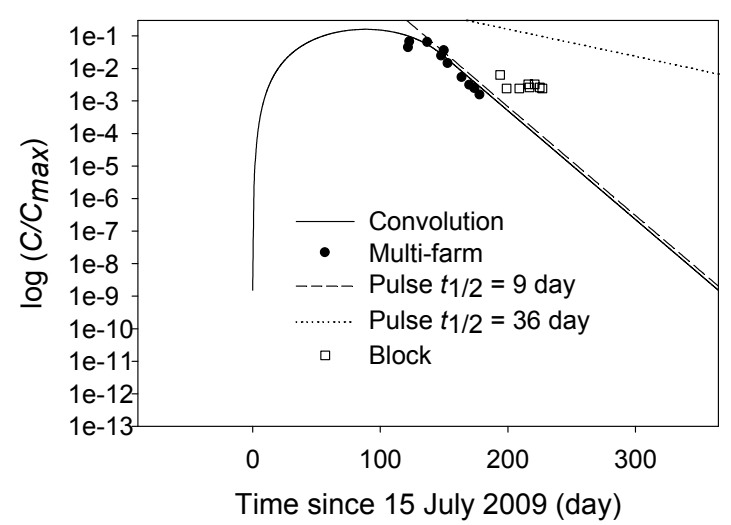

Figure 3. Comparison of scaled atrazine concentration from multi-farm and block data with convolution model and pulse model for various half-lives.

\section{CONCLUSIONS}

Pesticide concentrations from experimental blocks, multi-block and multi-farm catchments in the Mackay Whitsunday region of Queensland can be used to compare with the model of Cook et al. (2011). Qualitatively the experimental data show similarities to the shape of the concentration response with time predicted by the model.

The model can also be used along with the experimental data to estimate the half-life of various pesticides from different spatial scales. This shows that the calculated half-lifes were less at larger scales, however, there is no significant difference between the half- lives with scale except for atrazine. The half-lives tend to be less than values used previously for tropical catchments (PPDB, 2009). These half-life values are also consistent with peak concentration differences found experimentally and calculated with the model of Cook et al. (2011).

These results suggest that the up-scaling model of Cook et al. (2011) will have utility in estimating the mass of pesticide in surface soil at a catchment scale, concentrations in runoff and in interpreting experimental data.

\section{REFERENCES}

Carroll, C., D. Waters, S.Vardy, D.M.Silburn, S. Attard, P.J. Thorburn, A.M. Davis, N. Halpin, M. Schmidt, B. Wilson, and A. Clarke (2011). A paddock to reef monitoring and modelling framework for the Great Barrier Reef. Paddock and catchment component. Agriculture Environment and Ecosystems (in press).

Cook, F.J., J.H. Knight, D.M. Silburn, R.S. Kookana, and P.J. Thorburn (2011). Upscaling from paddocks to catchments of pesticide mass and concentration in runoff . Agriculture Environment and Ecosystems (in press).

Finlayson, B., and M. Silburn (1996). Soil, nutrient and pesticide movements from different land use practices, and subsequent transport by rivers and streams. National Conference on Downstream Effects of Land Use, Rockhampton Australia, April 1995. Eds H.M. Hunter, A.G. Eyles and G.E. Rayment. 
Haynes, D., P. Ralph, J. Prange, and B. Dennison (2000). The impact of the herbicide diuron on photosynthesis in three species of tropical seagrass. Marine Pollution Bulletin, 41: 288-293.

Holz G.K., and P.G. Shields (1984) SOILS. In 'Mackay Sugar Cane Land Suitability Study'. (Queensland Department of Primary Industries: Brisbane)

Isbell R.F. (1996) The Australian soil classification. In 'Australian Soil and Land Survey Handbook Vol 4'. (CSIRO Publishing: Collingwood).

Jones, R. (2005). The ecotoxicological effects of Photosystem II herbicides on corals. Marine Pollution Bulletin, 51: 495-506.

Leonard, R.A., G.W. Langdale, and W.G. Fleming, J. (1979). Herbicide Runoff from Upland Piedmont Watersheds_-Data and Implications for Modeling Pesticide Transport1. J. Environ. Qual., 8: 223 229.

Lewis, S.E., J.E. Brodie, Z.T. Bainbridge, K.W. Rohde, A.M. Davis, B.L. Masters, M. Maughan, M.J. Devlin, J.F. Mueller, and B. Schaffelke (2009). A new threat to the Great Barrier Reef. Environmental Pollution, 157: 2470-2484.

Packett, R., C. Dougall, K. Rohde, and R. Noble (2009). Agricultural lands are hot spots for annual runoff polluting the southern Great Barrier Reef lagoon. Marine Pollution Bulletin, 58: 976-986.

PPDB (2009). The pesticide properties database (PPDB) developed by the Agriculture \& Environment Research Unit (AERU), University of Hertfordshire, funded by UK national sources and the EUFunded FOOTPRINT project (FP6-SSP-022704).

Rohde, K. and A. Bush (2011). Paddock to sub-catchment scale water quality monitoring of sugarcane management practices.. Interim Report 2009/2010 wet season, Mackay Whitsunday region. Queensland Department of Environment and Resource Management, for Reef Catchments Mackay Whitsunday Inc., Australia, 49p.

Selim H.M. and H. Zhu (2005). Atrazine sorption-desorption hysteresis by sugarcane mulch residue. Journal of Environmental Quality, 34: 325-335.

Shaw, M., M. Furnas, K. Fabricius, D. Haynes, G. Eaglesham, and J.F. Mueller (2010). Monitoring pesticides on the Great Barrier Reef. Marine Pollution Bulletin, 60(1): 113-122.

Smith R., S. Vardy, R. Turner, and M. Warne (2011) Can we predict concentrations at the end of catchment sites using convolution integral model? MODSIM11.

Silburn, D.M. and I.R. Kennedy (2007). Rain simulation to estimate pesticide transport in runoff. In 'Rational Environmental Management of Agrochemicals'. (Eds IR Kennedy, KR Soloman, SJ Gee, AN Crossan, S Wang, F Sanchez-Bayo) pp. 120-135. ACS Symposium Series No. 966. American Chemical Society.

Willis, G.H., McDowell, L.L., Southwick, L.M., and Smith, S. (1987). Methoxychlor and endosulfan concentrations in unit-source runoff and in channel flow of a complex watershed. Transactions of the ASAE, 30: 394-399. 